\title{
Thoracoscopic Talc Insufflation Versus Talc Slurry in Patients with Malignant Pleural Effusion
}

\author{
Ahmed U. ElMasry, Mohamed A. Amr, Hany A. Eldomiaty, and \\ El-Sayed A. Fayad ${ }^{*}$
}

Department of Cardiothoracic Surgery, Faculty of Medicine, Suez Canal University, Ismailia, Egypt

\begin{abstract}
Background: Malignant Pleural Effusion (MPE) is defined as an accumulation of pleural fluid in which malignant cells are present. It is a poor clinical indicator as it represents an advanced stage neoplasm with median survival ranging from one to 12 months. Aim: We aimed at comparing Thoracoscopic Talc Insufflation with tube thoracostomy talc slurry pleurodesis in regard to the efficacy and complications in patients with MPE. Patients and Methods: 128 patients with MPE were divided into two groups, 64 in each. One group had tube thoracostomy talc slurry (TS) pleurodesis while the other had thoracoscopic talc insufflation (TTI) pleurodesis. Results: Talc slurry was associated with a longer hospital stay. Complications recorded included chest pain (TS 29\%, TTI $25.4 \%$ ), dry cough (TS 16\%, TTI 39\%), vomiting (TS 29\%, TTI 13.6\%), tachycardia (TS $16.13 \%$, TTI $18.64 \%$ ), surgical wound infection (TS $11.29 \%$, TTI 10.17\%), and respiratory failure complicating talc pneumonitis (TS 3.23\%, TTI 0\%). Pleurodesis success was enhanced by the presence of lung cancer (OR 2.34, $\mathrm{p}=0.02$ ) or breast cancer ( $O R 2.55, p=0.03$ ) as the primary malignancy, the younger the patient's age at pleurodesis time (OR 1.004, $p=0.89$ ) and the higher the pleural fluid glucose content (OR 1.01, $p=0.09)$. Pleurodesis failure was strongly correlated to the presence of any of the pre-procedural factors, female gender, hepatocellular carcinoma as the primary malignancy, and low pH pleural fluid. Conclusion: In MPE patients with no evidence of lung trapping, talc pleurodesis method used should depend on local expertise (availability of thoracoscopy), whether additional tissue is needed for molecular-marker analysis (would favor thoracoscopy), plus patient-related factors (operable or not). However, TTI has a significant irrefutable benefit in patients with adhesions and trapped lung.
\end{abstract}

Keywords: Malignant pleural effusion, thoracoscopic talc insufflation, thoracostomy talc slurry, pleurodesis

\section{Introduction}

Normally a $10-20 \mathrm{ml}$ of pleural fluid is spread between the visceral and parietal pleurae facilitating movement between the lungs and chest wall. This fluid is similar in composition to plasma yet lower in protein content (less than $1.5 \mathrm{gm} / \mathrm{dl}$ ). It originates mainly in the pleural capillaries and the interstitial spaces of the lung to be reabsorbed through the lymphatic vessels in the parietal pleura by means of stomas or through transcytosis ${ }^{(1,2)}$. The accumulation of this fluid, i.e., within the pleural space, is called a Pleural Effusion. This accumulation can occur because of various pathogenic mechanisms simply by impairing the balance between fluid production and reabsorption, i.e., by increasing the rates of pleural fluid formation exceeding 
the rates of fluid reabsorption. Of these pathogenic causes, malignancy is one of the most common representing about $22 \%$ of all effusions ${ }^{(2,3)}$. Malignant Pleural Effusion (MPE) is defined as an accumulation of pleural fluid in which malignant cells are present. It is considered as a poor clinical indicator as it represents an advanced stage neoplasm with a median survival ranging from one to 12 months. Putting that in mind, together with the fact that, in as many as $20 \%$ of patients, MPE accounts for the first clinical presentation of malignancy; the management of such patients is predominantly palliative in nature, focused mainly on relieving the patients' symptoms together with prevention of recurrence. This palliation requires the use of the most effective method that ensures both shortening of in hospital stay time and reducing outpatient clinic visits to the minimum together with being as much painless as possible and having the least reported complications ${ }^{(3-5)}$. Excluding patients with expected poor survival of one month or less at time of diagnosis and those with trapped lungs; there is a consensus that chemical pleurodesis, i.e., chemical irritation of the pleural space to induce inflammation that closes the space by fibrosis, is the best definitive pleural intervention to be applied in patients with MPE who have re-expandable lung after thoracocentesis. Though many sclerosant agents have been proposed for this purpose, talc remains the most effective due to its high success rate together with being the cheapest and the most widely available agent ${ }^{(6-11)}$. Two methods of talc delivery are present. These are talc slurry injection through chest tube thoracostomy and talc poudrage (insufflation) during thoracoscopic surgery. Up till now, no evidence is present to support either of them as the best method to be used in cases with MPE. This guided the current opinion to suggest using either of them according to the patient's condition, i.e., to use the method that best fits with each patient separately. Still, it should be kept in mind that the method used should also inflect the least complications and shortens the hospital stay time as much as possible ${ }^{(7,8)}$. In our study, we aimed at identifying the method that best answers three main questions; (1) which method achieves the best results regarding its success? (2) which method inflects the least complications over the patient?; and (3) which method is associated with the minimum need for hospital stay and outpatient clinic visits?

\section{Patients and Methods}

\section{Study design}

The study sample was drawn from patients with MPE attending our emergency department and outpatient clinic between March 2019 and April 2020. We used stratified randomization as the patients were arranged according to their gender into two groups, males and females. Each patient was then given a randomly generated number using "Microsoft Office Excel 2016 random number generator function". The numbers were then arranged as either even or odd. Patients were then allocated into two groups: group A (Talc Slurry group), which included patients with even numbers (males \& females), and group B (Talc Insufflation group), which included patients with odd numbers (males \& females). The results were analyzed for their level of significance and were considered statistically significant if the $p$ value is $\leq$ 0.05 and highly significant if the $p$ value is $\leq$ 0.01 . Patients included in the study were chosen based on the following inclusion criteria; (1) they all had clinically confident diagnosis of MPE requiring pleurodesis which was defined as a recurrent symptomatic pleural effusion with histocytologically proven pleural malignancy or in the context of histocytologically proven 
malignancy elsewhere without a clear alternative cause for fluid accumulation. (2) They were expected to have a survival time of more than 3 months. Patients were excluded from the study if they had any of the following exclusion criteria; (1) patients younger than 18 years old, (2) female patients who are pregnant or lactating, (3) patients with encysted or septated pleural effusion, (4) patients presenting with respiratory failure, (5) patients complaining of dyspnea in spite of complete evacuation of the pleural effusion, (6) patients with trapped lungs who have incomplete lung expansion following complete evacuation of the pleural effusion, (7) patients with evident chest infection with clinical and / or laboratory signs suggestive of parapneumonic effusion (turbid pleural fluid with fluid $\mathrm{pH}$ less than 7.2, LDH more than 1000 $\mathrm{IU} / \mathrm{L}$, glucose less than $40 \mathrm{mg} / \mathrm{dl}$ and differential TLC equal to or more than $10000 / \mathrm{ml}$ effusion with more than 50\% neutrophils $)^{(2,12)}$, and patients presenting with decompensated liver disease (Child-Pugh class B \& C) ${ }^{(13)}$.

\section{Surgical techniques}

Patients' preparation for the procedure started with thoracocentesis using chest tube thoracostomy (size $24-32 \mathrm{Fr}$.). The daily output of the chest drain was followed up until it reached less than $200 \mathrm{cc}$ of clear effusion fluid per 24 hours. After ensuring that the lung is fully inflated and there is no air leak through the chest tube the patient was considered ready for pleurodesis. In group A (Talc Slurry or TS group), premedication with Lidocaine $2 \%$ as a local anesthetic agent was done to all cases. It was injected into the pleural cavity through the chest tube. The dose was calculated according to the patient's weight as $3-5 \mathrm{mg} / \mathrm{Kg}$ with a ceiling of $250 \mathrm{mg}$ diluted in normal saline $0.9 \%$ for a total volume of $50 \mathrm{ml}$. Then, four to five grams of graded sterile talc powder mixed with 50 $\mathrm{ml}$ of normal saline $0.9 \%$ forming talc slurry was injected through the chest drain followed by a flush of $50 \mathrm{ml}$ of normal saline. The tube is clamped and the sclerosing agent is left in the pleural cavity for 6 hours during which the patient is instructed to move freely to ensure that the sclerosing agent reaches all parts of the pleural cavity. The chest drain is then declamped and left in place until the daily drainage of pleural fluid is under $200 \mathrm{ml}$ of clear effusion fluid. Following drain removal, the patient is discharged and is followed up on outpatient basis. In group B (Thoracoscopic Talc Insufflation or TTI group), patients had an ipsilateral intercostal nerve block to minimize the postoperative surgical wound pain to the minimum. This was followed by general anesthesia using double lumen endotracheal tube in order to provide single lung ventilation with controlled isolation of the lung on the side of pleurodesis with continuous oxygen saturation, pulse \& blood pressure monitoring during the procedure. The chest tube used for pleural fluid evacuation was removed and single port video assisted thoracoscopic surgery (VATS) was used. The chest cavity was first evaluated, and any residual effusion was removed using suction. Biopsies were taken from any suspicious masses, nodules or lesions for histopathological examination. Four to five grams of graded sterile talc powder were insufflated under vision over the two layers of pleurae to ensure a uniform distribution of talc over the whole surface of the pleural membrane. A chest drain (size ranging from $24-32 \mathrm{Fr}$.) was then inserted into the pleural space through the same port of VATS. Then the thoracoscopic opening and the opening of the old chest tube were closed in anatomical layers with the new chest tube fixed to the skin with sutures. Chest tube daily output was followed up until it reached less than $200 \mathrm{ml}$ of clear fluid. The drain was then removed, and patients were 
discharged and followed up on outpatient basis. Following pleurodesis, patients were managed as follow; they were admitted to the intermediate care unit either immediately before the process of talc slurry injection in the TS group or postoperatively in the TTI group. They were assessed for the occurrence of complications including recurrence of effusion, fever, pain, tachycardia, vomiting, cough, hypotension, hypoxia, respiratory distress, or failure. Fever was controlled using cold compresses; however, Acetaminophen (Paracetamol) was kept as a second line antipyretic in cases not improving on cold compresses. Chest pain was assessed using the Numeric Pain Rating Scale (NRS)(14) with the subjects addressing their pain levels as a number ranging from zero, which means no pain at all, to 10 which means the worst pain imaginable. Chest pain was managed using narcotic analgesics (Tramadol) with significant improvement of pain defined as a decrease of at least 2 on the scale compared to the initial assessment. The levels of pain were recorded daily until all subjects reported to be pain free. Other complications were managed symptomatically. Patients were closely monitored in the intermediate care unit for at least 24 hours and were transferred to the inpatient ward upon fulfilling the following discharge criteria; (1) absence of any reported complications for 24 hours after the procedure, (2) normalization of body temperature if fever occurred, (3) normalization of heart rate if tachycardia occurred, (4) chest pain level of less than 4 as reported by the patient according to the NRS, (5) absence of respiratory distress or hypoxia and (6) absence of hepatic encephalopathy in patients with liver disease.

\section{Data collection and endpoints}

The data collected consisted of (1) full history including data about gender, age, presence of any chronic illnesses \& type of primary malignancy. (2) Clinical examination of the patient's general condition and chest condition. (3) Laboratory investigations including arterial blood gases ( $A B G$ ), serum albumin, total proteins, lactate dehydrogenase enzyme (LDH) levels and chemical analysis of pleural fluid including $(\mathrm{pH}$, protein, $\mathrm{LDH}$, total leucocyte count (TLC) and glucose contents). (4) Cytological analysis of pleural fluid for malignant cells. (5) Radiological assessment of the patient using plain chest X-ray (postro-anterior (PA) and lateral views) before and after thoracocentesis. The study endpoint included three possibilities:(1) successful pleurodesis, (2) failure of pleurodesis and (3) patient mortality during the follow up period without a clear link to the procedure of pleurodesis in which case the patient was excluded from the study and considered as a dropped out case. Successful pleurodesis was considered if the patient achieved either (a) complete response (no recurrence) or (b) partial response (partial re-accumulation of pleural fluid on the same side of the procedure that does not require any further pleural intervention) throughout the post procedural three months follow up period.

Follow-up and assessment of the outcomes The total length of hospitalization for each patient was defined as the total period in days that begins with pleurodesis and ends at the day of discharge. It was calculated as the sum of the stay time in the intermediate care unit and the inpatient ward. Following hospital discharge, patients were followed up weekly in the first month then monthly for the following two months. Erect chest X-ray PA \& lateral views were done on each outpatient visit after the procedure to detect any ipsilateral recurrence of effusion. Failure of pleurodesis was defined as: (a) recurrence of pleural effusion (either free or encysted) on the same side of the procedure in the following three 
months causing respiratory symptoms to the patient or requiring another pleural intervention. (b) Development of ipsilateral empyema after pleurodesis, which was considered as failure since these patients required pleural fluid evacuation, which is a type of pleural intervention. (c) Patient's mortality as a complication of pleurodesis either by the complications that may accompany the method used including, as an example, the complications of anesthesia in case of thoracoscopy under general anesthesia, or by complications related to pleurodesis itself such as respiratory failure because of talc pneumonitis.

\section{Ethical Considerations}

A written informed patient consent was obtained from all patients before enrollment. The study was conducted in accordance with the guidelines of the Helsinki Declaration on human experimentation. Patients retained the right to refuse enrollment or withdraw from the study.

\section{Statistical Analysis}

Data were analyzed using IBM SPSS Statistics (22) Program and presented using tables and graphs. Normally distributed continuous data were expressed as mean \pm standard deviation. Significance tests used included chi-square test \& Fisher's exact test for qualitative data and t-test for quantitative data. The results were analyzed for significance and were considered statistically significant if the $p$ value is $\leq 0.05$ and highly significant if the $p$ value is $\leq 0.01$.

\section{Results}

A total of 128 cases diagnosed with malignant pleural effusion were included in our study; seven of which dropped out due to patient mortality before the end of the three months follow up post-procedural period leaving a total of 121 cases (62 in the
TS group \& 59 in the TTI group). The dropped-out cases were excluded from the study due to lack of a clear link suggesting that this mortality is an eventual complication of talc pleurodesis.

\section{Preoperative data}

Demographic characteristics (age, gender) are detailed in Table 1. Males and females allocation in each group was therefore found to be statistically insignificant regarding the results of the study $(p$ value $=$ 0.72). Similarly, age differences between the two study groups were found to represent no significant difference between both study groups ( $p$ value $=0.74)$. Total of 12 different primary malignancies were included in the study. The distribution of these malignancies in both study groups was found to represent no significant statistical difference regarding the results of the study ( $p$ value $=0.67)$. and primary malignancies (lung, breast, lymphoma, mesothelioma, prostate, colon and renal) were similar in both groups (Table 1).

\section{Postoperative outcomes}

The overall success rate in the study was found to range from $88.7 \%$ in talc slurry (TS) group to $94.9 \%$ in talc insufflation (TTI) group with only 10 failed cases. Regarding the first question that is, which method proves to be the most successful? Analysis of pleurodesis outcomes in each group of the study revealed that although talc insufflation had numerically less failure cases compared to talc slurry (three cases versus seven cases respectively); statistically, there is no significant difference between the two methods regarding all types of pleurodesis outcomes (Table 2). Meaning that, both have comparable rates of success and failure with neither of them being considered as more superior to the other one in this regard. Moreover, regarding the need for longer hospitalization, talc slurry was found to be associated with an overall longer hospital stay both in the 
intermediate care unit and in the inpatient ward. Data analysis revealed that the intermediate care stay in slurry patients increased up to 1.6 times that in insufflation patients reaching a mean of 2.31 days (SD \pm 1.25). Ward stay was also increased in talc slurry by 1.2 times with the mean stay reaching 5.77 days $(S D \pm 2)$. The total length of hospital stay was therefore increased by 1.3 times rising from a mean of 6.54 days ( $S D \pm 2.28$ ) in the TTI group to 8.1 days ( $S D \pm 2.43$ ) in the TS group.

\begin{tabular}{|l|c|c|}
\hline \multicolumn{3}{|c|}{ Table 1. Preoperative data in both study groups } \\
\hline Variables & \multicolumn{2}{c|}{ Method of Pleurodesis } \\
\hline & $\begin{array}{c}\text { Talc Slurry } \\
(\mathrm{n}=62)\end{array}$ & $\begin{array}{c}\text { Talc Insufflation } \\
(\mathrm{n}=59)\end{array}$ \\
\hline Age (Years) & $47.4 \pm 13.9$ & $55.1 \pm 11.7$ \\
\hline $\begin{array}{c}\text { Gender } \\
\text { Male }\end{array}$ & $38(61.3 \%)$ & $38(64.4 \%)$ \\
Female & $24(38.7 \%)$ & $21(35.6 \%)$ \\
\hline Primary malignancy & & \\
\hline Lung cancer & $21(33.87 \%)$ & $22(37.29 \%)$ \\
\hline Breast cancer & $14(22.58 \%)$ & $13(22.03 \%)$ \\
\hline Lymphomas & $9(14.52 \%)$ & $4(6.78 \%)$ \\
\hline Mesothelioma & $3(4.84 \%)$ & $7(11.86 \%)$ \\
\hline Prostate cancer & $2(3.23 \%)$ & $3(5.08 \%)$ \\
\hline Colon cancer & $3(4.84 \%)$ & $3(5.08 \%)$ \\
\hline Renal cell carcinoma & $1(1.61 \%)$ & $2(3.39 \%)$ \\
\hline Hepatocellular carcinoma & $3(4.84 \%)$ & $2(3.39 \%)$ \\
\hline Ovarian cancer & $2(3.23 \%)$ & $3(5.08 \%)$ \\
\hline Thyroid cancer & $1(1.61 \%)$ & $1(1.69 \%)$ \\
\hline Bladder cancer & $1(1.61 \%)$ & 0 \\
\hline Osteosarcoma & $1(1.61 \%)$ & 0 \\
\hline
\end{tabular}

Postoperative Complications

Seven different complications were recorded among patients during their hospital stay (Table 4). These include low grade fever (TS 61.3\%, TTI 20.3\%), chest pain (TS 29\%, TTI $25.4 \%$ ), dry cough (TS 16\%, TTI 39\%), vomiting (TS 29\%, TTI 13.6\%), tachycardia (TS $16.13 \%$, TTI $18.64 \%$ ), surgical wound infection (TS 11.29\%, TTI 10.17\%), and respiratory failure complicating talc pneumonitis (TS 3.23\%, TTI 0\%). Except for cough, other pleurodesis associated complications tended to be either more common in slurry patients (i.e., fever and vomiting) or equally common in both methods. Therefore, an overall number of complications was created by adding up all pleurodesis related complications into a single number and comparing the means of these numbers between both study groups (Table 4). The mean numbers were found to be 1.66 in TS group ( $S D \pm 1.17$ ) and 1.27 in TTI group ( $S D \pm 1.08)$, with the total sum of complications reaching 103 and 75 complications for the TS and TTI groups, respectively. These numbers, although numerically bigger in slurry patients, were statistically-insignificant, meaning that both techniques are similarly associated with the development of the same numbers of complications. Since the procedure of pleurodesis was found to insignificantly affect the outcomes, all pre procedural factors included in the study were analyzed as predictors of these outcomes. 


\begin{tabular}{|l|c|c|c|c|}
\hline \multicolumn{4}{|c|}{ Table 2. Pleurodesis Outcomes in Each Group } \\
\cline { 2 - 4 } & \multicolumn{3}{|c|}{ Method of Pleurodesis } & \multirow{2}{*}{ Overall } \\
\cline { 2 - 3 } & Talc Slurry & Talc Insufflation & & \\
\hline Success (Complete Response) & $70.97 \%$ & $83.06 \%$ & $76.86 \%$ & 0.115 \\
\hline Success (Partial Response) & $17.74 \%$ & $11.86 \%$ & $14.88 \%$ & 0.364 \\
\hline Failure (Recurrence) & $4.83 \%$ & $3.39 \%$ & $4.13 \%$ & 0.689 \\
\hline Failure (Empyema) & $3.23 \%$ & $1.69 \%$ & $2.48 \%$ & 0.588 \\
\hline Failure (Death) & $3.23 \%$ & $0 \%$ & $1.65 \%$ & 0.164 \\
\hline Overall Success & $88.71 \%$ & $94.92 \%$ & $91.74 \%$ & \multirow{2}{*}{0.215} \\
\hline Overall Failure & $11.29 \%$ & $5.08 \%$ & $8.26 \%$ & \\
\hline
\end{tabular}

Four of these were found to enhance pleurodesis success; namely, the presence of lung cancer (OR 2.34, $\mathrm{p}$ value 0.02) or breast cancer (OR 2.55, p value 0.03) as the primary malignancy, the younger the patient's age at time of pleurodesis (OR 1.004, $p$ value 0.89) and the higher the glucose content of the pleural fluid (OR 1.01, $p$ value 0.09 ). It is to be noted that, age and pleural fluid glucose level had small impact that does not have true statistical significance as independent predictors of success. Pleurodesis failure, on the other hand, was strongly correlated to the presence of any of three of the pre procedural factors; namely, female gender (OR 8, p value 0.011 ) hepatocellular carcinoma as the primary malignancy (OR 71.43, $\mathrm{p}$ value $<0.001$ ) and the presence of low pH in pleural fluid analysis (OR 320, $\mathrm{p}$ value 0.004). Patients with HCC draw special attention during the study, though all of them were classified as Child $A$ according to the Child-Pugh classification ${ }^{(13)}$ and therefore were fit for surgical intervention.

\begin{tabular}{|c|c|c|c|c|c|}
\hline \multicolumn{6}{|c|}{ Table 3. Length of Hospitalization in both study groups } \\
\hline & \multicolumn{4}{|c|}{ Method of Pleurodesis } & \multirow{3}{*}{$\mathrm{P}$} \\
\hline & \multicolumn{2}{|c|}{ Talc Slurry } & \multicolumn{2}{|c|}{ Talc Insufflation } & \\
\hline & Mean $( \pm S D)$ & Sum & Mean ( \pm SD) & Sum & \\
\hline Intermediate Care Stay (Days) & $2.31( \pm 1.25)$ & 143 & $1.54( \pm 1.01)$ & 91 & 0.001 \\
\hline Inpatient Ward Stay (Days) & $5.77( \pm 2)$ & 358 & $5( \pm 1.97)$ & 295 & 0.437 \\
\hline Total Hospital Stay (Days) & $8.08( \pm 2.43)$ & 501 & $6.54( \pm 2.28)$ & 386 & 0.005 \\
\hline
\end{tabular}

All these patients showed higher tendency towards the development of complications not only confined to the complications observed in other patients but also including worsening of their Child-Pugh classification with the development of up to grade III hepatic encephalopathy. Moreover, the mean of overall complications and length of hospitalization including intermediate care; ward and total hospital stay all increased by more than 1.5 folds in patients with HCC compared to other types of malignancies regardless of the method of pleurodesis used. Additionally, two factors were found to happen with increasing levels in cases with pleurodesis failure. These are the rates of pleurodesis complications (OR 32, p value $<0.001$ ) and the duration of hospital stay, which had an OR of 3.09, 2.08 and 1.83 for intermediate care, ward and total hospital stay lengths respectively with all of them showing an increase in their means reaching more than 1.5 times that of successful cases. 


\begin{tabular}{|c|c|c|c|c|c|}
\hline \multicolumn{6}{|c|}{ Table 4. Pleurodesis Complications in Each Group } \\
\hline & \multicolumn{4}{|c|}{ Method of Pleurodesis } & \multirow{3}{*}{$\mathrm{p}$ Value } \\
\hline & \multicolumn{2}{|c|}{ Talc Slurry } & \multicolumn{2}{|c|}{ Talc Insufflation } & \\
\hline & No & $\%$ & No & $\%$ & \\
\hline Low Grade Fever & 38 & 61.3 & 12 & 20.3 & $<0.001$ \\
\hline Vomiting & 18 & 29 & 8 & 13.6 & 0.038 \\
\hline Dry Cough & 10 & 16.13 & 23 & 39 & 0.005 \\
\hline Chest Pain & 18 & 29 & 15 & 25.4 & 0.091 \\
\hline Tachycardia & 10 & 16.13 & 11 & 18.64 & 0.72 \\
\hline Surgical Wound Infection & 7 & 11.29 & 6 & 10.17 & 0.842 \\
\hline Talc Pneumonitis \& Respiratory Failure & 2 & 3.23 & 0 & 0 & 0.164 \\
\hline Overall Number of Complications & $\begin{array}{c}\text { Mean } \\
1.66\end{array}$ & $\begin{array}{l}\text { Sum } \\
103\end{array}$ & $\begin{array}{c}\text { Mean } \\
1.27\end{array}$ & $\begin{array}{c}\text { Sum } \\
75\end{array}$ & 0.217 \\
\hline
\end{tabular}

\section{Discussion}

Definitive management of malignant pleural effusion remains a difficult decision since its main objective is just palliation of the patient's symptoms to minimize his/her suffering. Success and failure of pleurodesis were defined according to two main rules; the first is that the patient does not require any further pleural intervention on the same side after pleurodesis for at least 3 months. The second is that pleurodesis does not lead to patient mortality either by the complications that may accompany the method used including, as an example, the complications of anesthesia in case of thoracoscopy under general anesthesia, or by complications related to pleurodesis itself such as respiratory failure because of talc pneumonitis. The overall success rate in the study was $91.74 \%$ with only 10 failed cases representing $8.26 \%$.

\begin{tabular}{|c|c|c|c|}
\hline \multicolumn{4}{|c|}{ Table 5. Predictors of Pleurodesis Success } \\
\hline & & Odds Ratio & $\mathrm{p}$ \\
\hline \multirow[t]{2}{*}{ Primary Malignancy } & Lung Cancer & 2.34 & 0.02 \\
\hline & Breast Cancer & 2.55 & 0.03 \\
\hline Age & Younger than 59 years & 1.004 & 0.89 \\
\hline Pleural Fluid Analysis & Glucose $>55 \mathrm{mg} / \mathrm{dl}$ & 1.01 & 0.09 \\
\hline
\end{tabular}

This resembles the reported success rates of talc pleurodesis in general regardless of the method used as found throughout the literature ${ }^{(8)}$ and in the studies done by several researchers including Mark E. Roberts et al (9), Desai \& Lee ${ }^{(6)}$, loannis Psallidas et $\mathrm{al}^{(11)}$ and Shaaban A. et al ${ }^{(15)}$. Answering the first question regarding which method proves to be the most successful, the analysis of pleurodesis outcomes in each group of the study revealed that although talc insufflation had numerically less failure cases compared to talc slurry (three cases versus seven cases respectively); statistically, there is no significant difference between the two methods regarding all types of pleurodesis outcomes. Meaning that, both have comparable rates of success and failure with neither of them being considered as more superior to the other one in this 
regard. This comes in line with the current opinions regarding talc pleurodesis techniques $^{(8)}$; the 2010 British thoracic society ${ }^{(9)} \& 2018$ American thoracic society $(7)$ guidelines of MPE management and the recent reviews done to pleurodesis in literature $(5,6,11)$. Moreover, regarding the question of which method is associated with longer hospitalization period, we found that talc slurry is associated with significantly increased need for hospitalization both in the intermediate care unit and in the inpatient ward. The total length of hospital stay was therefore increased significantly by 1.3 times rising from a mean of 6.54 days (SD \pm 2.28 days) in insufflation patients to 8.1 days ( $S D \pm 2.43$ days) in slurry patients. This was reported by Desai \& Lee in their review ${ }^{(6)}$, Farghaly et al in their study ${ }^{(16)}$ and by the 2018 American thoracic society guidelines ${ }^{(7)}$. They agreed on that the median hospitalization period for talc pleurodesis ranges from 4- 7 days and that insufflation patients have shorter overall periods of hospital stay than slurry patients. This is considered as a significant advantage for insufflation over slurry technique. With both methods having comparable success rates and the insufflation method being more superior regarding the overall shorter hospitalization period; we have the last question to answer that is which method is associated with fewer complications than the other. Most studies usually discuss the overall complications associated with talc pleurodesis in general regardless of the method used without highlighting any differences in complications associated with each method. However, in our study we found that some complications may accompany each method significantly more often. The first and most reported complication is low grade fever with the patient's temperature ranging between $37.40 \mathrm{C}$ and $38.50 \mathrm{C}$. It represented a difficulty in its management since most drugs that suppress fever are mainly anti- inflammatory which may impair the pleurodesis itself rendering it less effective. However, in all reported cases cold compresses were enough to control the fever till it subsides spontaneously usually within 1 - 3 days from the procedure. It is worth mentioning that although Acetaminophen (Paracetamol) was always kept as a second line antipyretic; it was not required for use by any patient during their hospital stay. Fever is reported in the literature to occur in up to $68 \%$ of patients after pleurodesis regardless of the method used ${ }^{(6,7,16)}$. This was clearly observed in the slurry group with $61.3 \%$ of its cases suffering from fever. However, the Insufflation group had as little as $20.3 \%$ of its cases experiencing fever after the procedure. The difference between the two study groups might be caused by a more systemic inflammatory response that occurs in case of talc slurry. It is noted that the technique used for talc slurry pleurodesis involves occlusion of the chest drain after talc injection with instructing the patient to move freely to help distributing the slurry over the whole surface of the pleural membrane. Whereas in the insufflation technique; talc is distributed under vision using the thoracoscopic insufflator; thus, ensuring a more uniform distribution of talc without the need for chest tube occlusion. Like fever, post pleurodesis vomiting was also more common among slurry patients in comparison to insufflation patients (29\% and $13.6 \%$ respectively) and more common among females than males. Though vomiting is not usually reported as a complication of pleurodesis, in our study it occurred in up to $21.5 \%$ of the study group and responded well to symptomatic treatments. Another complication that was frequently met in our study is chest pain. Although the 2010 British thoracic society guidelines ${ }^{(9)}$, reported that up to $7 \%$ of patients may complain of significant chest pain during intrapleural administration of talc slurry despite 
premedication with Lidocaine as a local anesthetic drug; this was not the case in our study where no subject included reported having such type of pain. However, pain was usually reported few hours after pleurodesis, which was assessed using the Numeric Pain Rating Scale (NRS) ${ }^{(14)}$. Patients who experienced pain reported having a mixture of two types of pain; a deep burning sensation that involves the chest side on which the procedure took place in addition to a dull aching type of pain that was more intense at the site of chest tube insertion, the ipsilateral shoulder and ipsilateral side of the back. Patients in the insufflation group also reported having a dull aching pain at the site of the surgical wound. Pain levels ranged from zero to seven on initial assessment with the mean score ranging from 1.1 to 1.5 on the scale. Desai \& Lee ${ }^{(6)}$ in their review reported that in about $5-10 \%$ of patients chest pain can complicate pleurodesis regardless of the method used for talc administration. This rate was reported by Györik et al.(17) to reach up to $29 \%$ in patients undergoing thoracoscopic talc insufflation. Our study results partially agreed with both reviews as we found that the overall rate of chest pain occurrence reached an average of $27.3 \%$ in the whole sample and that there is indeed no significant statistical difference between the occurrence of pain in both study groups. Yet, we also found that pain was numerically more manifested in the slurry group (29\%) compared to the insufflation group (25.4\%) despite that patients in the latter group had larger surgical wound and were subjected to chest tube repositioning intraoperatively. This might be explained by the introduction of nerve block anesthesia in addition to general anesthesia during thoracoscopy, which is believed by us to be greatly responsible for reducing the rates of pain experienced by the patients in the insufflation group. The only complication that was significantly more associated with talc insufflation is post pleurodesis cough despite not being described as a common complication in the literature. Cough was mainly dry irritant in nature usually occurring few hours after the procedure and lasting for one to two days. It was more common in cases of talc insufflation than in talc slurry (39\% versus 16\% respectively) and more specifically in male patients of the insufflation group compared to female ones ( $52.6 \%$ versus $14.3 \%$ respectively). The occurrence of cough might be traced to two factors; the first and most notable is the use of double lumen endotracheal tubes, which were used in all cases of talc insufflation to achieve selective lung ventilation during thoracoscopy. These tubes, as described by Chen et al. ${ }^{(18)}$, are associated with up to $36 \%$ chances of inducing postoperative cough mainly due to their larger diameter, which can produce air way mucosal irritation, damage and inflammation releasing multiple cytokines eventually causing cough. Respiratory complications, on the other hand, including dyspnea, hypoxia, talc pneumonitis and respiratory failure are reported in the literature to be more often associated with the use of talc insufflation(7). According to Desai \& Lee ${ }^{(6)}$, respiratory failure might occur in up to $8 \%$ of insufflation patients compared to only $4 \%$ in slurry patients. This rate was reported by Shinno et al. ${ }^{(19)}$ to increase reaching up to $15 \%$ if talc pleurodesis is used in elderly patients who have an underlying interstitial abnormality of the lungs. Answering the first question of the study regarding the success and failure of talc pleurodesis generated a fourth secondary question that is; Can some of the factors included in the study be used as predictors of talc pleurodesis outcomes. Since the procedure of pleurodesis was found to insignificantly affect the outcomes, the answer to such a question may give a guide regarding the prediction of pleurodesis success (or failure) before the procedure takes place. All 
the pre procedural factors included in the study were therefore categorized into two main sections, predictors of success and predictors of failure. Factors that were taken into consideration included gender, age, the presence of other chronic illnesses, the type of primary malignancy and the results of pleural fluid analysis. Four of these were found to positively affect the outcomes of pleurodesis, namely, the presence of lung cancer or breast cancer as the primary malignancy, the younger the patient's age at time of pleurodesis and the higher the glucose content of the pleural fluid before pleurodesis. In their review of talc pleurodesis, Bielsa et al (20) reported that some malignancies can have an effect over the final outcomes of pleurodesis. They stated that breast cancer is usually associated with more success, whereas lung cancers are particularly prone to more failure compared to other types of malignancies. Our study partially agrees with these results, since we found that patients with breast cancer are indeed having more chances of success with an odds ratio (OR) of 2.55 ( $p$ value $=0.03$ ) compared to other types of malignancies. However, contrary to what was reported, patients with lung cancer in our study also had higher odds $(O R=2.34)$ of having a successful pleurodesis when compared to other patients ( $p$ value $=0.02$ ). Pleurodesis failure, on the other hand, was strongly correlated to the presence of any of three of the pre-procedural factors namely; female gender (OR = $8, \mathrm{p}$ value $=0.011)$, hepatocellular carcinoma as the primary malignancy ( $O R=$ 71.43, $\mathrm{p}$ value $<0.001)$ and the presence of low $\mathrm{pH}$ (lower than 7.4) in pleural fluid analysis (OR 320, $\mathrm{p}$ value $=0.004$ ). These factors were found to have a strong negative impact on the success of the procedure regardless of the method of pleurodesis used. Santos et al and Rafei et al in their studies ${ }^{(21,22)}$ concluded that both age and gender have no significant effects over pleurodesis outcomes. This might be partially true regarding age as an independent factor. However, in our study, we found that pleurodesis is particularly more prone to fail in female patients with an overall failure rate reaching $17.78 \%$ compared to only $2.63 \%$ in male ones. Lastly, both positive and negative association between different factors and success of pleurodesis are important to reveal. The positive associations can lead to installation of better techniques as well as customized guidelines for the indications of its performance. On the other hand, negative results can shift our attention in the choice of a method over another to more effective criteria.

\section{Study limitations and prospects}

The predictors of pleurodesis success in cases with malignant pleural effusion constitute a controversial field of study that seems not to be consistent throughout the literature and is mostly institution specific. It is worth an in-depth analysis to determine the factors that lead to a successful pleurodesis to increase the complete success rates. A better understanding is warranted knowing that the success rates of pleurodesis in this study as well as in other studies look dismal. Analyses performed over larger periods of time and on a bigger scale are needed to enhance the statistical power and generate consistent results that can be used as a database to ameliorate performance of this procedure.

\section{Conclusion}

In the light of this study, we can conclude that in patients with recurrent MPE who have expandable lung after thoracocentesis, talc is an effective sclerosant with a success rate ranging from $88.7 \%$ to $94.9 \%$ in achieving chemical pleurodesis. Such success is not dependable on the method talc delivery, wither it was in the form of slurry 
through a chest drain or by thoracoscopic insufflation, since both methods have comparable rates of success and failure with neither of them being more superior to the other one in this regard. Nevertheless, thoracoscopic talc insufflation was found to have the advantage of significantly reducing the need for hospital stay both in the intermediate care unit and the inpatient ward; together with being associated with either fewer or similar complications to talc slurry. However, in cases with MPE who have expandable lung with no evidence of lung trapping undergoing talc pleurodesis, the method of delivery should be tailored according to the patient overall condition. The decision to use one method over the other should depend on several factors including local expertise (i.e., availability of thoracoscopy), whether additional tissue is needed for molecularmarker analysis (would favour thoracoscopy), as well as patient-related factors (operable or not).

Conflicts of interest: The authors declare that they have no competing interests.

\section{Ethics approval and consent to participate:} Due to the retrospective nature patients, consent for publication was waved.

Availability of data and material: Available by the corresponding author upon request.

Funding: Not applicable

Authors' contributions: E.F., A.E. and M.A. participated in getting the conception, data collection, analysis, and manuscripts writing. All authors read and approved the final manuscript.

\section{References}

1. Light RW. Clinical practice. Pleural effusion. N Engl J Med. 2002; 346 25):1971-7.
2. Na MJ. Diagnostic tools of pleural effusion. Tuberc Respir Dis (Seoul). 2014;76(5):199-210.

3. Gorden J, Fathi J. Malignant Pleural Effusion Evaluation and Management. Curr Respir Med Rev. 2012;8:314-21.

4. Bakr R, El-Mahalawy I, Abdel-Aal G, Mabrouk A, Ali A. "Pleurodesis using different agents in malignant pleural effusion. Egyptian Journal of Chest Diseases and Tuberculosis. 2013;61(4).

5. Penz E, Watt KN, Hergott CA, Rahman NM, Psallidas I. Management of malignant pleural effusion: challenges and solutions. Cancer Manag Res. 2017;9:229-41.

6. Desai NR, Lee HJ. Diagnosis and management of malignant pleural effusions: state of the art in 2017. J Thorac Dis. 2017;9(Suppl 10):S1111-s22.

7. Feller-Kopman DJ, Reddy CB, DeCamp $M M$, Diekemper RL, Gould MK, Henry $\mathrm{T}$, et al. Management of Malignant Pleural Effusions. An Official ATS/STS/STR Clinical Practice Guideline. Am J Respir Crit Care Med. 2018;198(7):839-49.

8. Moorjani N, Viola NS, Walker W. Key Questions in Thoracic Surgery. 1 ed. Harley, editor. United Kingdom: TFM Publishing Ltd; 2015. 641-59 p.

9. Roberts ME, Neville E, Berrisford RG, Antunes G, Ali NJ. Management of a malignant pleural effusion: British Thoracic Society Pleural Disease Guideline 2010. Thorax. 2010;65 Suppl 2:ii32-40.

10. Vaz MC, Marchi E, Vargas FS. Pleurodesis: technique and indications. J Bras Pneumol. 2006; 32 (4): 347-56.

11. Psallidas I, Kalomenidis I, Porcel JM, Robinson BW, Stathopoulos GT. Malignant pleural effusion: from bench to bedside. Eur Respir Rev. 2016;25(140):189-98.

12. He T, Oh S. Diagnostic approach to pleural effusions. AME Medical Journal. 2018;3. 
13. Peng Y, Qi X, Guo X. Child-Pugh Versus MELD Score for the Assessment of Prognosis in Liver Cirrhosis: A Systematic Review and Meta-Analysis of Observational Studies. Medicine (Baltimore). 2016;95(8):e2877.

14. Correll DJ. The Measurement of Pain: Objectifying the Subjective. In: SD W, editor. Pain Management. Philadelphia: Saunders/Elsevier; 2007. p. 197211.

15. Yo SA, Mo EB, El AA, Ah EH, Hassan MS. Comparison between thoracoscopic pleurodesis results by talc, doxycycline poudrage, and silver nitrate slurry in patients with malignant pleural effusion. Egypt J Chest Dis Tuberc. 2020;69(1):105-11.

16. Farghaly A, Allama A, Nashy M, El-HagAly $M$, Abdel El-Sadek S. Smallcaliberttube†drainage and rapid pleurodesis in malignant pleural effusion. Menoufia Medical Journal. 2018;31(1):163-8.

17. Györik S, Erni S, Studler U, HodekWuerz R, Tamm M, Chhajed PN. Longterm follow-up of thoracoscopic talc pleurodesis for primary spontaneous pneumothorax. Eur Respir J. 2007; 29(4):757-60.
18. Chen Z, Dong Q, Liang L. Effect of different thoracic anesthesia on postoperative cough. J Thorac Dis. 2018;10(6):3539-47.

19. Shinno $Y$, Kage $H$, Chino $H$, Inaba A, Arakawa $S$, Noguchi $S$, et al. Old age and underlying interstitial abnormalities are risk factors for development of ARDS after pleurodesis using limited amount of large particle size talc. Respirology. 2018;23(1):55-9.

20. Bielsa S, Hernández $P$, RodriguezPanadero F, Taberner T, Salud A, Porcel JM. Tumor type influences the effectiveness of pleurodesis in malignant effusions. Lung. 2011; 189 (2): 1515.

21. Rafei H, Jabak S, Mina A, Tfayli A. Pleurodesis in malignant pleural effusions: Outcome and predictors of success. Integrative Cancer Science and Therapeutics. 2015;2.

22. Santos PS, Marques MA, Cruz C, Monteiro H, Fradinho F. Predictors of talc slurry pleurodesis success in patients with malignant pleural effusions. Rev Port Pneumol (2006). 2017;23(4):216-20. 